\title{
Safety and pH Measurements of Sushi Rice in Japanese Restaurants in Burnaby BC, Canada
}

\author{
Celine Jiyun Lee ${ }^{1}$, Helen Heacock ${ }^{2}$ \\ 1 Lead Author, B. Tech Student, School of Health Sciences, British Columbia Institute of Technology, 3700 Willingdon Ave. Burnaby, BC V5G 3H2 \\ 2 Supervisor, School of Health Sciences, British Columbia Institute of Technology, 3700 Willingdon Ave. Burnaby, BC V5G 3H2
}

\begin{abstract}
Background and Purpose: The increasing popularity of sushi in Metro Vancouver raises public health concerns over the consumption of sushi rice being held out of temperature control. Although sushi rice is acidified to control growth of pathogenic microorganisms, there is no existing documented system to monitor the $\mathrm{pH}$ of sushi rice, and $\mathrm{pH}$ testing is rarely performed by Environmental Health Officers(EHOs)/Public Health Inspectors(PHIs) during routine inspections. The purpose of the study was to measure the $\mathrm{pH}$ of sushi rice samples collected from different sushi restaurants in Burnaby, BC and determine whether the $\mathrm{pH}$ meets the accepted standard of 4.6 or below.

Methods: 30 sushi rice samples were collected from 30 randomly selected sushi restaurants in Burnaby, British Columbia. The samples were kept at room temperature and then tested for $\mathrm{pH}$ using the Waterproof Palm $\mathrm{pH}$ Meter. Results: The mean $\mathrm{pH}$ of the samples was 4.09; the median was 4.115; the standard deviation was 0.198; and the range was 0.82 with the minimum value of 3.71 and the maximum value of $4.53 .100 \%$ ( 30 out of 30 samples) had the $\mathrm{pH}$ less than 4.6. The statistical z-test resulted in a p-value of 0.00 .

Discussion: All of the sushi rice samples had $\mathrm{pH}$ values less than 4.6. Therefore, the samples were adequately acidified to inhibit the growth of pathogens. The low $\mathrm{pH}$ values indicate that the samples are not considered potentially hazardous food, thus safe to be stored at room temperature for extended periods of time. However, due to the nature of Bacillus cereus that can grow at a $\mathrm{pH} 4.3$ or higher, the target $\mathrm{pH}$ of sushi rice is 4.3 or lower.

Conclusion: Inadequately acidified sushi rice may pose a health risk if it is stored out of temperature control. The study shows that sushi rice being consumed by the public in Burnaby, BC is generally safe and has a low public health concern. Therefore, EHOs/PHIs can feel assured that sushi rice stored at room temperature is unlikely to cause potential foodborne illness.
\end{abstract}

Keywords: sushi, rice, pH, acidity, food safety, Bacillus cereus, Staphylococcus aureus, Burnaby, BC

\section{Introduction}

Sushi, which literally means 'seasoned rice', is a type of Japanese cuisine consisting of acidified rice combined with various toppings and fillings, usually raw fish or other ingredients (Bargen, 2011). Since globalization has introduced sushi to many countries, it has gained a huge popularity across the world and has become a part of Canadian diets today. There are more than 400 sushi restaurants in Metro Vancouver, and the number of sushi restaurants is increasing every year.

As much as sushi is favored and consumed by many Canadians, it possesses potential health risks. Uncooked fish can be easily contaminated by various pathogens and may cause foodborne illness and other diseases. For example, Anisakiasis is caused by anisakis, a parasitic nematode found in raw seafood. $90 \%$ of all cases of anisakiasis described in the literature are caused by the consumption of sushi and sashimi (Bucci et al., 2013). Patients generally recover on their own, but surgery is often necessary for invasive anisakiasis that penetrates the intestine, liver and lungs (Sakanari \& McKerrow, 1989).

Health concerns of eating sushi have been recognized since many people are aware of the risk of raw fish consumption. However, public awareness of risks associated with sushi rice is low. Sushi rice is generally kept at room temperature or in warm holding unit in most sushi restaurants as sushi is supposed to be served warm (about $30^{\circ} \mathrm{C}$ ) for the ideal taste. The control measure to keep the sushi rice safe at room temperature is the addition of a vinegar solution to reduce its $\mathrm{pH}$ to inhibit growth of harmful bacteria.

Environmental Health Officers (EHOs) or Public Health Inspectors (PHIs) have difficulty ensuring safety of sushi rice because each sushi chef uses his/her own recipe with differing amounts of the vinegar solution, and a $\mathrm{pH}$ test of sushi rice is rarely performed during inspections.

The focus of this study was to determine safety of sushi rice stored out of temperature control $\left(4^{\circ} \mathrm{C}-60^{\circ} \mathrm{C}\right)$ by creating a $\mathrm{pH}$ database of sushi rice collected from various sushi restaurants in the City of Burnaby, BC.

\section{Literature Review \\ What is Sushi?}

History of Sushi: The origin of sushi is believed to be fermented fish or meat for the purpose of preservation in the second century in Southeast Asia (Sushi Encyclopedia, 
2007). Later on, rice was used to speed up the fermentation process. In the sixteenth century, vinegar was beginning to be added to further reduce the preparation time. This type of sushi was preferred over the original one and became a delicacy in Japan. From this point onward, fermentation was not favored anymore, and a new type of sushi using only vinegar and cooked rice began to evolve. Sashimi (slices of raw fish) was consumed for centuries in Japan, but it was in the early 1880's when raw fish and rice were first combined. This acidified rice with raw fish is the sushi widely known to the world today. During 1970s, sushi was first introduced in North America as Japanese businesses started expanding to the U.S. (Sushi Encyclopedia, 2007).

Types of Sushi: There are two main types of sushi sold in Burnaby: nigiri sushi and maki sushi (Figure 1). Literally translated, nigiri means "hand-pressed". Nigiri sushi is small, oval shaped acidified rice with a firmly placed topping, such as slices of raw fish or other ingredients. Maki sushi is a cylindrical shaped roll consisting of acidified rice and fillings such as seafood, meat, and vegetables (Bargen, 2011).

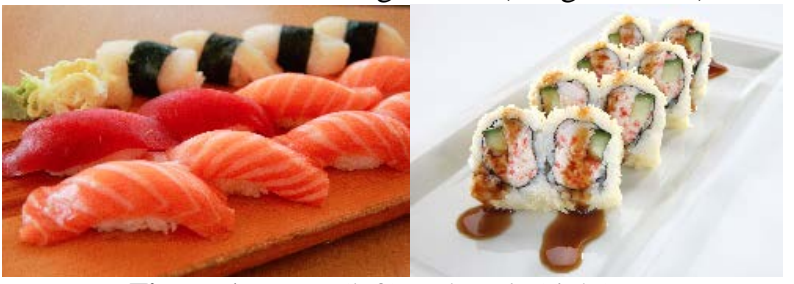

Figure 1. Nigiri (left) and Maki (right)

\section{Factors Affecting the Growth and Survival of Microorganisms in Food}

Cooked rice is a potentially hazardous food (PHF) (BCCDC, 2006). According to Food Premise Regulation, potentially hazardous food is food that is "capable of supporting the growth of disease-causing microorganisms or the production of toxins” (Food Premise Regulation BC, 1999). There are two types of factors that affect microbial growth on potentially hazardous food: intrinsic and extrinsic factors. Intrinsic factors include water activity ( $\mathrm{Aw}$ ), oxygen availability, acidity $(\mathrm{pH})$, available nutrients, and presence and identity of natural microbial flora. Extrinsic factors include temperature, relative humidity, atmosphere composition and packaging (Forsythe, 2010). The factors which can be controlled to limit microbial growth in sushi rice include acidity $(\mathrm{pH})$, water activity $(\mathrm{Aw})$ and temperature.

Water activity (Aw): Water activity (Aw) is a measure of the available water content in a food sample. The Aw is calculated by the ratio of the water vapour pressure of the sample to that of pure water at the same temperature. Water activity ranges in value from 0.0 to 1.0. The Aw of pure water is 1.0 and the value decreases with the addition of solutes (Forsythe, 2010). Most microorganisms cannot survive in the environment where the Aw is lower than 0.86 . Leung (2006) measured the Aw of sushi rice made by the recipe provided by SushiLink (2006). The Aw of the sushi rice was 0.962 which is far above 0.86 . This indicates that water activity does not play an important role in inhibiting growth of microorganisms in sushi rice.

Temperature: Temperature is one of the most important factors in safe food handling practices. Temperature values for microbial growth have a range with an optimum temperature for maximal growth. The temperature range between $4^{\circ} \mathrm{C}$ and $60^{\circ} \mathrm{C}\left(40^{\circ} \mathrm{F}\right.$ and $\left.140^{\circ} \mathrm{F}\right)$ is the Danger Zone where most bacteria grow (FoodSafe, 2006). If the temperature is greater than $60^{\circ} \mathrm{C}$, most bacteria die. If the temperature is colder than $4^{\circ} \mathrm{C}$, the bacteria stay alive but do not multiply rapidly. Storing sushi rice at room temperature for extended hours is clearly temperature abuse unless other factors such as $\mathrm{pH}$ are controlled to inhibit microbial growth. Acidity (pH): $\mathrm{pH}$ is a measure of acid concentration in a food sample with a range of 0 to 14 (Forsythe, 2010). The $\mathrm{pH}$ range for a microorganism, like the temperature range, has a minimum and a maximum value with an optimum $\mathrm{pH}$. Generally, the optimum $\mathrm{pH}$ of most bacteria is 6.8-7.2, and they cannot survive at $\mathrm{pH} 4.6$ or lower. The $\mathrm{pH}$ range of plain white rice is 6.0-6.7 which falls into the range of the optimum $\mathrm{pH}$ of most bacteria (Forsythe, 2010).

\section{Pathogens Associated with Sushi Rice}

Most microorganisms are killed during the rice cooking process. However, handling cooked rice is more important than the cooking process because cooked rice provides a good environment for pathogen growth. The primary pathogens of concern associated with cooked rice are Bacillus cereus and Staphylococcus aureus. In addition, sushi rice can be easily cross-contaminated by other pathogenic bacteria as well because sushi rice is always handled with sushi chef's bare hands that touch raw fish and other ingredients at the same time.

Bacillus cereus: B. cereus is a spore-forming bacterium which may cause foodborne illness (Labbe and Garcia, 2001). Among various Bacillus species found in a wide variety of foods, $B$. cereus is most commonly associated with foodborne illness outbreaks. B. cereus produces toxins that cause illness. There are two recognized types of $B$. cereus foodborne illness: diarrheal (watery diarrhea, abdominal cramps and pain) and emetic (nausea and vomiting) (Forsythe, 2010). Diarrheal type of B. cereus is associated with meats, milk, vegetables, and fish. B. cereus-producing emetic toxin is found in rice and starchy food products (Forsythe, 2010). Rice can be easily contaminated by $B$. cereus during growth, harvesting, processing and handling (Haque and Russell, 2005). The spores of B. cereus survive during boiling and frying rice and germinate when the environment is favorable for growth (Gilbert et al, 1974). Between 1973 and 1985, B. cereus caused 17.8\% of the total bacterial food poisoning in Finland, 0.8\% in Scotland, 0.7\% in Japan and 2.2\% in Canada (Kotiranta et al, 2000). Growth requirements of $B$. cereus are as follows (Forsythe, 2010):

- $\quad$ Minimal water activity (Aw) is 0.930 
- $\quad$ Temperature range is $4^{\circ} \mathrm{C}-52^{\circ} \mathrm{C}$

- $\quad$ pH range is 4.3-9.3

The minimum water activity of $B$. cereus is lower than the average Aw of sushi rice, meaning that sushi rice provides enough moisture to support growth of $B$. cereus. The minimum $\mathrm{pH}$ that $B$. cereus can multiply is 4.3 , which is slightly lower than general minimum $\mathrm{pH}$ for inhibition of pathogens. This indicates that $B$. cereus may grow on sushi rice if the $\mathrm{pH}$ is higher than 4.3.

Staphylococcus aureus: S. aureus is a toxin-producing bacterium commonly found on the skin and in the noses and throats up to $25 \%$ of healthy people (CDC, 2006). Most of S. aureus foodborne illness cases are caused by poor hygiene of food handlers and improper food handling practices. Symptoms usually develop within 1 to 6 hours after consumption of the contaminated food. Infected individuals experience nausea, vomiting, abdominal cramps, and often diarrhea (Forsythe, 2010). Poor personal hygiene and inappropriate food handling techniques increase the chance of $S$. aureus transferred to sushi rice.

Growth requirements of $S$. aureus are as follows (Forsythe, 2010):

- Minimal water activity is 0.83

- $\quad$ pH range is $4.0-10$

- $\quad$ Temperature range is $7^{\circ} \mathrm{C}-48^{\circ} \mathrm{C}$

$S$. aureus can grow in the environment with low water activity (minimum 0.83) and low pH (minimum 4.0). This again indicates that storing sushi rice at room temperature will support the growth of $S$. aureus and toxin production if the $\mathrm{pH}$ is higher than 4.0 .

Other potential pathogenic microorganisms: Although $B$. cereus and $S$. aureus are the primary pathogens of concern, sushi rice possesses a high potential for cross-contamination by other pathogens as well since it involves considerable bare hand contact. Escherichia coli is one of the common pathogens known to have caused outbreaks associated with sushi restaurants.

Escherichia coli is commonly found in the digestive tract of all animals including humans. The presence of $E$. coli is used as an indicator of fecal contamination (Labbe and Garcia, 2001). Sushi handlers who have poor personal hygiene may transfer $E$. coli to sushi rice while making sushi with bare hands. Inadequate $\mathrm{pH}$ and temperature abuse will support $E$. coli growth and cause foodborne illness. It was found that the E. coli outbreak in Nevada was caused by poor food-handling practices and infected foodhandlers in sushi restaurants, resulting in 130 reported illnesses (Jain et al., 2008).

\section{Sushi Rice Preparation}

Acidification of rice: Rice is acidified by adding a vinegar solution to reduce its $\mathrm{pH}$ enough to inhibit microbial growth, especially $B$. cereus and $S$. aureus. The acetic acid in vinegar lowers the $\mathrm{pH}$ of the rice and acts as a bacterial inhibitor (Wilson, 2001). Acidified sushi rice is known to be safe at room temperature for up to 8 hours (University of Florida, 2004).

White Sushi Rice vs. Brown Sushi Rice: Sushi rice is commonly made of white rice. Brown rice is not typically acidified due to the harder surface coating on the rice which limits penetration of acid solutions. Due to this reason, the cooked brown sushi rice must be stored under refrigeration at $4^{\circ} \mathrm{C}$ or below to reduce the chance of foodborne illness (University of Florida, 2004).

\section{Legislation and Guidelines}

BC Food Premise Regulation does not specify control measures for sushi rice. However, pursuant to section 14(2), "every operator of food premises must ensure that potentially hazardous food is stored or displayed at a temperature of not more than $4^{\circ} \mathrm{C}$ or not less than $60^{\circ} \mathrm{C}$ ” (BC Food Premises Regulation, 1999). Acidified rice with $\mathrm{pH} 4.6$ or less is not considered a potentially hazardous food as the $\mathrm{pH}$ will inhibit the growth of pathogens (University of Florida, 2004). This indicates that sushi rice should be refrigerated unless its $\mathrm{pH}$ is lower than 4.6.

BC Centre for Disease Control (BCCDC) released a sushi safety handout in 2010. It states that the $\mathrm{pH}$ of white sushi rice should be less than 4.6 to inhibit bacterial growth. Rice should be acidified as soon as it is cooked and discarded at the end of the day (BCCDC, 2010).

Health Authorities throughout North America have their own guidelines on sushi and sushi rice to ensure customer safety. For example, Alberta Health Services requires a written recipe for sushi rice with the amount of rice and acidification agent added to the rice (Alberta Health Services, 2011). In the County of San Bernardino, California, if sushi rice is to be held at between $4^{\circ} \mathrm{C}$ and $60^{\circ} \mathrm{C}$, operators are required to submit a HACCP plan with a $\mathrm{pH}$ test result submitted from an accredited laboratory to the Health Authority. Operators also need to measure the $\mathrm{pH}$ of their sushi rice monthly using a $\mathrm{pH}$ test strip paper to ensure the $\mathrm{pH}$ is lower than 4.6 (Environmental Health Services, San Bernardino, 2008).

However, Health Authorities in Metro Vancouver Vancouver Coastal Health and Fraser Health - do not currently have guidelines regarding sushi rice safety. EHOs/PHIs conduct inspections in sushi restaurants, but $\mathrm{pH}$ of sushi rice is rarely checked due to the semi-solid nature of rice that involves complicated on-site measurement or laboratory testing. This study will provide a good database for EHOs/PHIs to assess the general safety of sushi rice in Burnaby and will be a great tool to educate operators on the importance of $\mathrm{pH}$ control of sushi rice.

\section{Relevant Previous Research on Sushi Rice}

The key factors in testing safety of sushi rice are $\mathrm{pH}$ value and microbial analysis. Mundo et al. (2005) investigated how sushi rice formulation affects $\mathrm{pH}$ and water activity (Aw) of rice and inhibits growth of Bacillus cereus. Twelve different commercial sushi rice recipes were used and the formulation 
mainly consists of vinegar, sugar and salt. The study results indicate that $B$. cereus growth is most significantly inhibited by $\mathrm{pH}$ (Mundo et al., 2005). Hence, $\mathrm{pH}$ should be accurately measured and monitored to prevent growth of $B$. cereus in sushi rice.

Sushi rice with pH 4.6 or lower is known to be safe at room temperature for extended hours since it is not considered a potentially hazardous food any more. Leung (2006), a former BCIT Environmental Health student, conducted an experiment to investigate a correlation between total aerobic bacterial growth and the number of hours that the sushi rice is left at room temperature. The results show that bacterial counts increased in the first 3 hours and declined in the next 3 hours (Leung, 2006). Although the hump shape pattern in the third hour needs further investigation to be explained, the study could not find any health risk of storing sushi rice out of safe temperature zone for extended hours (up to six hours) as long as the $\mathrm{pH}$ of the sushi rice is less than 4.6. While Leung's study focused on biological analysis of sushi rice made for the experiments, this study focuses on $\mathrm{pH}$ of actual sushi rice samples being consumed by the public.

Some studies were conducted to investigate the chemical and biological quality of sushi rice that is actually served to the consumers. Sushi rice samples collected from 19 restaurants in Seattle were tested for $\mathrm{pH}$ and microbiological analysis (Adams et al, 1994). All of them had pH levels 4.6 or lower, and no fecal coliforms were detected. Bacillus cereus and Staphylococcus aureus were detected in the samples from 6 restaurants, but the levels were too low to be considered a public health concern (Adams et al, 1994).

A similar study was done by New South Wales Food Authority (2008) which conducted a survey of food handling practices and microbiological quality of sushi in Australia. Sushi rice samples were also collected to measure $\mathrm{pH}$, water activity, and microbiological quality. It was found that the $\mathrm{pH}$ of sushi rice was rarely confirmed after acidification process, resulting in $15 \%$ of the samples with a greater $\mathrm{pH}$ than 4.6. Although the microbiological quality of samples was generally acceptable, low levels of $B$. cereus and $S$. aureus were detected in some samples, indicating a potential health risk if proper acidification does not take place (NSW Food Authority, 2008).

This study was based on the principle of the studies conducted in Seattle and Australia. However, microbiological analysis was not included in the study due to limited technical resources.

\section{Purpose of the Research Project}

The purpose of this research project was to measure the $\mathrm{pH}$ of sushi rice samples collected from different sushi restaurants in Burnaby and determine whether the $\mathrm{pH}$ meets the satisfactory level - 4.6 or below - as suggested by BCCDC.

\section{Methods and Materials}

The researcher visited 30 Japanese restaurants in the City of Burnaby and collected an acidified white sushi rice sample from each restaurant (Figure 2). The restaurants were randomly selected - every second sushi restaurant on Urbanspoon (2013). Collected samples were kept at room temperature, transported to the researcher's house and prepared for $\mathrm{pH}$ measurement. 15g of each sample was used. Due to the semi-solid nature of rice, each sample was ground using a mortar and pestle, and distilled water was added to obtain fluidity. Waterproof Palm pH Meter was calibrated with buffer solutions -4.00 and 7.00. The $\mathrm{pH}$ of each sample was measured using the Waterproof Palm pH Meter (Model PH220A).

Figure 2. Map of Randomly Selected 30 Japanese Restaurants in Burnaby (Google Map, 2013)

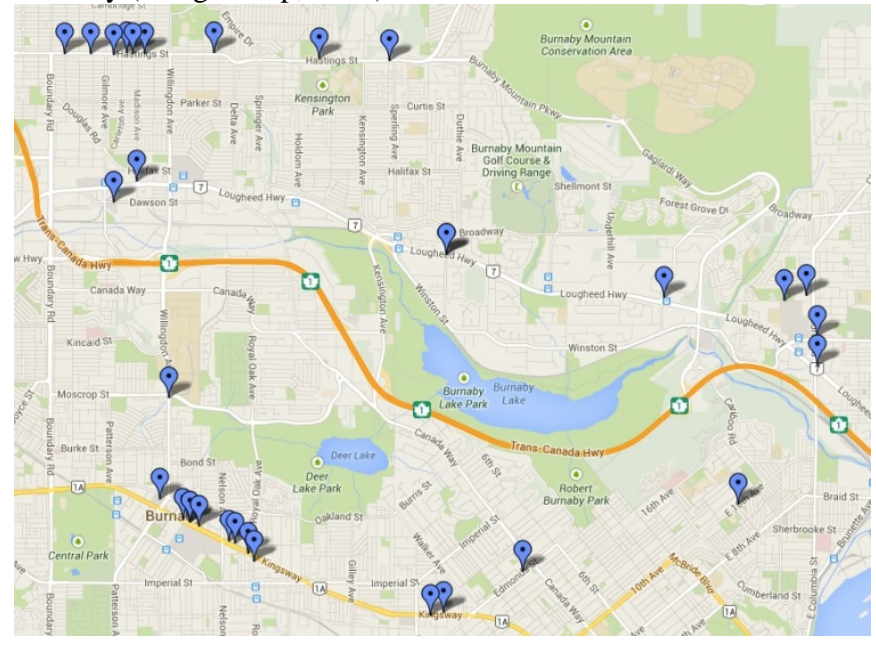

\section{Reliability and Validity of Measures}

Accuracy of Equipment: Waterproof Palm pH Meter was calibrated frequently to get the most accurate readings. The device itself provides accurate and reliable measurements if it is frequently calibrated and properly used. The manufacturer's instructions of Waterproof Palm pH Meter were strictly followed to increase accuracy of data collected. Measurement Techniques: In addition to the equipment, a good measurement technique is important to obtain accurate results. The same amount of the samples (15g) was used to measure the $\mathrm{pH}$ to minimize potential errors. Crosscontamination was prevented by thoroughly washing the electrode and other apparatus with distilled water after each use. The experiment was performed by only one researcher in a consistent fashion.

External Environment: Temperature as well as $\mathrm{pH}$ was recorded to ensure the sushi rice samples are held out of temperature control $\left(4^{\circ} \mathrm{C}-60^{\circ} \mathrm{C}\right)$. The temperature was measured by the Waterproof Palm pH Meter. 


\section{Inclusion and Exclusion Criteria}

Any acidified white rice stored out of temperature control in Japanese restaurants in Burnaby, BC is eligible for this experiment. Other food items, such as non-acidified rice, acidified brown rice, acidified white rice with other ingredients added, and refrigerated acidified white rice, were excluded from this study.

\section{Pilot Study}

A pilot study was conducted to examine feasibility of an approach and identify modifications needed in the design of the larger hypothesis testing study (Leon et al., 2011). 3 sushi rice samples were randomly collected from 3 different Japanese restaurants in Burnaby, and the $\mathrm{pH}$ of each sample was measured by the Waterproof Palm pH Meter. The results of the pilot study were evaluated to confirm that the materials, equipment and experimental procedure are capable of measuring $\mathrm{pH}$ of sushi rice samples.

\section{Results}

The obtained $\mathrm{pH}$ data of 30 sushi rice samples underwent a statistical test to analyze statistical significance. The obtained data are numeric and continuous. Numeric continuous data is a measurement on a continuum, such as temperature and $\mathrm{pH}$ (Heacock \& Sidhu, 2013a).

\section{Inferential Statistics}

Z-test was performed to compare the $\mathrm{pH}$ of the samples to $\mathrm{pH}$ 4.6, the maximum $\mathrm{pH}$ of sushi rice suggested by $\mathrm{BC}$ Centre of Disease Control (BCCDC, 2010). Z-test compares the mean of the population to a specific value (Heacock \& Sidhu, 2013b). The hypotheses of this study are as follows:

Null hypothesis (Ho): $\mu>4.6$

Alternative hypothesis (Ha): $\mu \leq 4.6$

The null hypothesis predicts that the mean of the $\mathrm{pH}$ of sushi rice in Burnaby is greater than 4.6. The alternative hypothesis predicts that the mean of the $\mathrm{pH}$ data is equal or less than 4.6.

Probability, $\mathrm{p}=0.05$ (or $5 \%$ ), was used as a significance level to evaluate statistical significance. If $p<0.05$, the researcher concludes that there is a significant difference between the mean of the data and the standard value, 4.6, and rejects the null hypothesis. If $\mathrm{p} \geq 0.05$, the researcher concludes that the results are not statistically significant at the $5 \%$ level, thus does not reject the null hypothesis.

Microsoft Excel 2013 and NCSS 9 were used to conduct a statistical z-test. The obtained data was arranged in a table using MS Excel 2013 and then transferred to NCSS. Z-test is equivalent to 'One-Sample T-Test' in NCSS (Hintze, 2013). Instructions of running the z-test (or one-sample t-test) were provided in the NCSS manual (Hintze, 2013).

\section{Collected Data}

Table 1 refers to the $\mathrm{pH}$ values of sushi rice samples collected from 30 different Japanese restaurants in Burnaby. Descriptive Statistics: Descriptive statistics of the $\mathrm{pH}$ data were analyzed (Table 2). The results show that the mean of the samples is 4.09; the median is 4.115; the standard deviation is 0.198 ; and the range is 0.82 with the minimum value of 3.71 and the maximum value of 4.53 . Among the 30 samples, no sample exceeded the $\mathrm{pH}$ 4.6.

Statistical Results: The results of the z-test (one-sample ttest) of the data were obtained. The $p$-value is $0.000(p<0.05)$. The null hypothesis was rejected at $\alpha=0.05$. The power for the null hypothesis is 1.000 at both $\alpha=0.05$ and $\alpha=0.01$. The data is normally distributed according to Skewness, Kurtosis and Omnibus Normality tests.

Interpretation: The normally distributed data confirms that a parametric statistical test was appropriate. Since the p-value is 0.000 , the null hypothesis was rejected at $\alpha=0.05$, and the researcher concluded that there is a statistically significant difference between the mean $\mathrm{pH}$ of the sushi rice samples collected and the standard value, 4.6. The alternative hypothesis was therefore not rejected, indicating that the $\mathrm{pH}$ of the sushi rice samples is less than 4.6.

Table 1. $\mathrm{pH}$ values of the sushi rice samples collected from 30 different Japanese restaurants in Burnaby

\begin{tabular}{|c|c|c|c|}
\hline Sample & Restaurants & pH & Temp $\left({ }^{\circ} \mathrm{C}\right)$ \\
\hline 1 & Kilala Sushi & 3.83 & 19.5 \\
\hline 2 & Kokoro Sushi & 3.82 & 21.2 \\
\hline 3 & Sushi S & 3.8 & 21.8 \\
\hline 4 & Yo Sushi & 3.71 & 21.1 \\
\hline 5 & Sushi Town & 3.8 & 22.9 \\
\hline 6 & Osaka Sushi & 3.91 & 23 \\
\hline 7 & Hong Sushi & 3.92 & 21.9 \\
\hline 8 & Black Dragon & 4.09 & 21 \\
\hline 9 & Nao Sushi & 4.04 & 20.9 \\
\hline 10 & Fresh Box Sushi & 4.16 & 21.8 \\
\hline 11 & Narita Sushi & 3.86 & 20.7 \\
\hline 12 & Sushi Garden Metrotown & 4.28 & 21.2 \\
\hline 13 & Tang Tang Sushi & 4.24 & 21.4 \\
\hline 14 & Osaka Island & 4.07 & 22.3 \\
\hline 15 & Kamamarui & 4.48 & 22.6 \\
\hline 16 & Sushi Garden Brentwood & 4.24 & 23 \\
\hline 17 & Asakusa Sushi & 4.09 & 22.6 \\
\hline 18 & Yakko & 4.19 & 22.8 \\
\hline 19 & Akira & 4.36 & 21.9 \\
\hline 20 & Sushi \& & 4.05 & 22 \\
\hline 21 & Gaya Sushi & 4.15 & 22.2 \\
\hline 22 & Kato Sushi & 4.18 & 22.4 \\
\hline 23 & Sushi Gen & 4.02 & 22.1 \\
\hline 24 & LA Sushi & 4.23 & 21.9 \\
\hline 25 & Sushi California & 4.53 & 22 \\
\hline 26 & Okoman Sushi & 4.16 & 22.4 \\
\hline 27 & Kita Sushi & 4.19 & 22.7 \\
\hline 28 & Sushi Oyama & 4.14 & 22.8 \\
\hline 29 & Little Toko's Sushi & 4.11 & 22.5 \\
\hline 30 & Sushi Kaku & 4.12 & 22.6 \\
\hline
\end{tabular}


Table 2. Descriptive Statistics of $\mathrm{pH}$ of the sushi rice samples

\begin{tabular}{|c|c|}
\hline Mean & 4.09 \\
\hline Median & 4.115 \\
\hline Mode & 3.8 \\
\hline Standard Deviation & 0.198 \\
\hline Range & 0.82 \\
\hline Minimum & 3.71 \\
\hline Maximum & 4.53 \\
\hline Count & 30 \\
\hline \multicolumn{2}{|c|}{ Calculated by Microsoft Excel 2013 (MS Excel, 2013) } \\
\hline
\end{tabular}

\section{Discussion}

A common method carried out by EHOs/PHIs to ensure the safety of sushi rice is to educate operators to discard temperature-abused sushi rice after 2 hours since it has been made. Generally, potentially hazardous food is considered safe if it is consumed in 2 hours because it does not allow sufficient time for the pathogenic growth that causes foodborne illness. If sushi rice has $\mathrm{pH} 4.6$ or below, then it is safe to be stored at room temperature for up to 8 hours (University of Florida, 2004).

As of December 2013, 56 Japanese restaurants are operating in Burnaby. The 30 collected samples represent about $57 \%$ of the total restaurants. The average $\mathrm{pH}$ value of the samples was 4.09 , ranged from 3.71 to 4.53 . The fact that all of the samples randomly collected for the experiment had the $\mathrm{pH}$ value less than 4.6 indicates that the samples were sufficiently acidified to inhibit the growth of pathogens, especially Bacillus cereus and Staphylococcus aureus, at the temperature above $4^{\circ} \mathrm{C}$. In other words, the sushi rice samples were not considered potentially hazardous food, thus safe to be stored out of temperature control for extended hours. The $\mathrm{pH}$ values are slightly lower than the values from other previous research that identified some samples with the unacceptable $\mathrm{pH}$ values. The study conducted in Australia by NSW Food Authority showed that $15 \%$ of sushi rice samples had a $\mathrm{pH}$ value greater than 4.6, having an average $\mathrm{pH}$ of 5.3 and a maximum level of 6.8 (NSW Food Authority, 2008). A similar study conducted in Seattle had an average $\mathrm{pH}$ value of 4.3, ranged from 3.9 to 4.6 (Adams et al., 1994). In another study reported by a former BCIT student, Leung (2006) used a commercial sushi rice recipe to make sushi rice, and the $\mathrm{pH}$ was found to be 4.2 , which is greater than the average $\mathrm{pH}$ value of the sushi rice samples collected in Burnaby. 23 out of 30 samples had a $\mathrm{pH}$ of less than 4.2. Therefore, the researcher is confident to conclude that sushi rice being consumed by the public in Burnaby is generally safe as all of the samples met the standard value of 4.6 or less as suggested by BCCDC.

However, the standard $\mathrm{pH}$ value of 4.6 to determine whether a food is a potentially hazardous food or not does not completely eliminate the possibility of all pathogenic growth. The pathogens of concern with sushi rice, such as $B$. cererus and $S$. aureus, can grow in a wide range of $\mathrm{pH}$. The minimum $\mathrm{pH}$ that $B$. cereus can grow is 4.3 (Forsythe, 2010).
This means that $B$. cereus may slowly grow in high-acid environment even if the $\mathrm{pH}$ is less than 4.6. Improper cooling of cooked rice prior to acidification provides the environment for the growth of $B$. cereus. 3 samples of sushi rice in this study had the $\mathrm{pH}$ greater than 4.3. Although the $\mathrm{pH}$ of all of the three samples was less than 4.6, both B. cereus and $S$. aureus may still potentially grow. $S$. aureus may grow when the $\mathrm{pH}$ is 4.0 or higher (Forsythe, 2010). 22 samples out of 30 had $\mathrm{pH}$ of 4.0 or greater. This indicates that the majority of the samples may allow the growth of $S$. aureus at room temperature. Considerable bare hand contact when handling sushi rice and poor hygiene of food handlers increase the chance of introducing $S$. aureus to sushi rice. However, the risk can be reduced by frequent and proper hand washing and proper food handling techniques.

Food is preserved by various controlling techniques that limit microbial growth. Hurdle technology is a common method to preserve food by using multiple techniques simultaneously to increase the overall effectiveness (Leistner \& Gorris, 1995). For example, a food product is acidified to lower the $\mathrm{pH}$ and then refrigerated to inhibit microbial growth. However, the only control measure for sushi rice is acidification. High water activity (Aw) of sushi rice and temperature abuse provides an optimal environment for microbial growth. This emphasizes the importance of adequate acidification of sushi rice as there is no other hurdle. In this case, the $\mathrm{pH}$ value greater than 4.3 may not be sufficient to limit the growth of $B$. cereus even if it is less than the standard value of 4.6 .

$B$. cereus is commonly associated with cooked rice. It produces spores that may not be destroyed by cooking. The spores will germinate when the conditions are met, and the germinated $B$. cereus will start to multiply (Labbe and Garcia, 2001). Considering the notable foodborne illness history of $B$. cereus, the safe limit of $\mathrm{pH}$ of sushi rice should be 4.3 or less. This means that the three samples with the $\mathrm{pH}$ greater than 4.3 need further acidification to lower the $\mathrm{pH}$ in order to ensure the safety of the sushi rice.

It is important to note that other ingredients of sushi affect the overall $\mathrm{pH}$ of the finished sushi. Even with a low $\mathrm{pH}$ of sushi rice, other ingredients may increase the total $\mathrm{pH}$ of the sushi products. For example, the ingredients of a California roll, such as avocado, cucumber and imitation crab meat, have a pH greater than acidified sushi rice (US FDA, 2008), increasing overall $\mathrm{pH}$. This indicates that sushi products maki and nigiri - are potentially hazardous food once made, and therefore should not be stored at room temperature.

\section{Limitations}

The measured $\mathrm{pH}$ value of each sushi rice sample may not accurately represent the $\mathrm{pH}$ of the whole batch of sushi rice. Vinegar solution may have had not been distributed evenly to the cooked rice, resulting in inaccurate reading. In addition, only $15 \mathrm{~g}$ of each sample was used once to measure the $\mathrm{pH}$ in this study. Taking multiple samples from each sample 
collected will increase the accuracy of the $\mathrm{pH}$ values and decrease potential errors.

Furthermore, although the sample size is large and represents greater than $50 \%$ of the total Japanese restaurants in Burnaby, there is a possibility that one or more restaurants which were not part of this study may have inadequately acidified sushi rice. Any batch of inadequately acidified sushi rice provides the opportunity and conditions for pathogens to grow and may cause foodborne illness. Also, it is difficult to ensure the consistency of the amounts of vinegar added to acidify rice. Food handlers may not follow their recipe and add different amounts of vinegar solution when they prepare sushi rice. Lastly, the periods of time that the sushi rice samples were held out of temperature control vary because it was not possible to track the exact time when the fresh rice was cooked and when the rice was acidified.

\section{Recommendations}

The existing guidelines of Fraser Health and Vancouver Coastal Health do not specify sushi rice safety. A mandatory $\mathrm{pH}$ testing from an accredited laboratory is recommended as part of a food safety plan to ensure the safety of sushi rice. Operators also need to monitor the $\mathrm{pH}$ of the sushi rice on a regular basis in order to reduce the health risk associated with inadequately acidified sushi rice. $\mathrm{pH}$ monitoring devices, such as $\mathrm{pH}$ test strips and a digital $\mathrm{pH}$ meter, should be available on-site. The $\mathrm{pH}$ of sushi rice should meet the standard value of 4.6 or less. However, target $\mathrm{pH}$ is 4.3 or less to completely inhibit potential growth of $B$. cereus. EHOs/PHIs should ensure that operators understand the public health significance of the $\mathrm{pH}$ of sushi rice and maintain proper handling techniques to prevent cross contamination. During routine inspections, it is recommended that EHOs/PHIs carry $\mathrm{pH}$ test strips or a $\mathrm{pH}$ meter to check the $\mathrm{pH}$ of sushi rice.

Acidified white rice with a $\mathrm{pH}$ less than 4.6 is not considered a potentially hazardous food, thus can be stored at room temperature for extended hours. Acidification should take place as soon as the rice is cooked (BCCDC, 2010). Rice should be made fresh daily and discarded at the end of the day. Acidified brown rice should be stored under refrigeration temperature below $4^{\circ} \mathrm{C}$ (BCCDC, 2010).

\section{Future Research}

1. Microbiological analysis of sushi rice is recommended along with a $\mathrm{pH}$ test to monitor growth of some potential pathogens, such as Bacillus cereus and Staphylococcus aureus.

2. Conduct a similar study for other cities in Metro Vancouver to assess general safety of sushi rice being consumed by the public.

3. Measure the $\mathrm{pH}$ of sushi rice over time to monitor a potential association between $\mathrm{pH}$ value and time.
4. Develop simple $\mathrm{pH}$ testing equipment that enables $\mathrm{EHOs} / \mathrm{PHIs}$ and operators to measure more accurate $\mathrm{pH}$ of sushi rice on-site.

\section{Conclusion}

Sushi rice is commonly stored at room temperature or in a warm holding unit for the ideal warm taste. However, inadequately acidified sushi rice may pose a health risk if it is stored out of temperature control. The study results show that sushi rice being consumed by the public in Burnaby, BC is generally safe with the $\mathrm{pH}$ below 4.6 and therefore has a low public health concern. However, due to lack of other control measures and the nature of $B$. cereus which may grow in a low $\mathrm{pH}$ environment, it is recommended that $\mathrm{pH}$ of sushi rice is 4.3 or lower.

\section{Acknowledgements}

The authors thank the British Columbia Institute of Technology - Environmental Health for supporting this research.

\section{Competing Interest}

The authors declare that they have no competing interests.

\section{References}

Adams, A.M., Leja, L.L., Jinneman, K., Beeh, J., Yuen, G.A., \& Wekell, M.M. (1994). Anisakid Parasites, Staphylococcus aureus and Bacillus cereus in Sushi and Sashimi from Seattle Area Restaurants. Journal of Food Protection. 57(4). Pp. 311-317(7)

Alberta Health Services. (2011). Guidelines for the Preparation of Sushi Products. Retrieved from http://www.albertahealthservices.ca/EnvironmentalHealth/wf-ehguidelines-for-sushi-prep.pdf

Bargen, V. (2011). Sushi: the edible art from Japan. Hinnerk Restaurant Business. 110(6). p. 46-47.

BC Centre for Disease Control. (2006). Food safety guidelines for soup kitchens. Retrieved from http://www.bccdc.ca/NR/rdonlyres/5C3B59A0-5873-4DE6AC05-B00627C5994/0/SoupKitchenGuide.pdf

BC Center of Disease Control. (2010). Sushi Safety. Retrieved from http://www.bccdc.ca/NR/rdonlyres/6D69540B-61B9-4FBDAD87-C9F954618219/0/SushiHandout_Dec2010.pdf

Bucci, C., Gallotta, S., Morra, I., Fortunato, A., Ciacci, C., \& Lovino, P. (2013). Anisakis, just think about it in an emergency! International Journal of Infectious Diseases. Retrieved from http://www.ncbi.nlm.nih.gov/pubmed/23850538

Centers for Disease Control and Prevention. (2006). Staphylococcal Food poisoning. Retrieved from 
http://www.cdc.gov/ncidod/dbmd/diseaseinfo/staphylococcus_fo od_g.htm

County of San Bernardino Environmental Health - Land Use Services. (2008). Sushi Rice HACCP Plan Packet. Retrieved from

http://www.sbcounty.gov/uploads/dph/dehs/Depts/Environmental Health/EHSDocuments/SushiRiceHACCPPlanPacket.pdf

Forsythe, S. J. (2010). The Microbiology of Safe Food. $2^{\text {nd }}$ Edition. New York: Blackwell Publishing Ltd. Pp. 69-70

Gilbert, R.J., Stringer, M.F., \& Peace, T.C. (1974). The survival and growth of Bacillus cereus in boiled and fried rice in relation to outbreaks of food poisoning. The Journal of Hygiene. 73(3): 433-444

Google Map. (2013). represents the locations of randomly selected 30 sushi restaurants in Burnaby, BC.

Haque, A. \& Russell, N.J. (2005). Phenotypic and genotypic characterisation of Bacillus cereus isolates from Bangladeshi rice. International Journal of Food Microbiology. 98: 23-34.

Heacock, H. \& Sidhu, B. (2013a). Research Methods Module 5. Descriptive Statistics. Scales of Measurement [PowerPoint Slides]. September 26, 2013.

Heacock, H. \& Sidhu, B. (2013b). Research Methods Module 5. Inferential Statistics. Z-test. [PowerPoint slide]. October 21, 2013.

Hintze, J. (2013). NCSS 9. NCSS, LLC. Kaysville, Utah, USA. www.ncss.com

Jain, S., Chen, L., Dechet, A., Hertz A.T., Brus, D.L., Hanley, K., Wilson, B., Frank, J., Greene, K.D., Parsons, M., Bopp, C.A., Todd, R., Hoekstra, M., Mintz, E.D., \& Ram, P.K. (2008). An outbreak of enterotoxigenic Escherichia coli associated with sushi restaurants in Nevada, 2004. Clinical Infectious Diseases. 47(1):1-7

Kotiranta, A., Lounatmaa, K., \& Haapasalo, M. (2000). Epidemiology and pathogenesis of Bacillus cereus infections. Microbes and Infection. 2(2), 189-198.

Labbe, R. G., \& Garcia, S. (2001). Guide to foodborne pathogens. New York: John Wiley and Sons, Inc. p. 52-59.

Leistner, L. \& Gorris, L.G.M. (1995). Food preservation by hurdle technology. Trends in Food Science and Technology. Retrieved from http://foodsafetyinfo.net/food_board/data/food_board9/Hurdle\%2 0technology.pdf

Leung, S. (2006). How safe it is to store sushi rice at room temperature? British Columbia Institute of Technology. Unpublished Research Project.

Leon, A.C., Davis, L.L, \& Kraemer, H.C. (2011). The role and interpretation of pilot studies in clinical research. Journal of Psychiatric Research. 45(5):626-9.
Microsoft Excel. (2013). Use the Analysis ToolPak to perform complex data analysis. Retrieved from http://office.microsoft.com/en-ca/excel-help/use-the-analysistoolpak-to-perform-complex-data-analysis-

HA102748996.aspx\#_Toc340479271

Mundo, M.A., Roue, A., Worobo, R.W., \& Padilla-Zakour, O.I. (2005). Sushi rice formulation affects $\mathrm{pH}$ and water activity, and inhibits growth of Bacillus cereus. 67-6.

NSW Food Authority. (2008). Report on food handling practices and microbiological quality of sushi in Australia. Retrieved from http://www.foodauthority.nsw.gov.au/_Documents/science/Micro biological-quality-of-sushi-in-Australia.pdf

Russell, L.B. (2011). Japanese Seasoned Sushi Rice. Prevention. Retrieved from http://www.prevention.com/food/cook/sushi-rollbowl?page $=3$

Province of British Columbia. Ministry of Advanced Education. (2006). FoodSafe Level 1 Student Workbook. $4^{\text {th }}$ Ed. Victoria: p.36-38

Public Health Act. Food Premise Regulation BC. (1999). Retrieved from

http://www.bclaws.ca/EPLibraries/bclaws_new/document/ID/free side/11_210_99\#section14

Sakanari, J.A., \& McKerrow, J.H., (1989). Anisakiasis. American Society of Microbiology. Clinical Microbiology Review. 2(3). pp.278-284.

Sushi Encyclopedia. (2007). History of sushi. Retrieved from http://www.sushiencyclopedia.com/sushi/history_of_sushi.html

Sushi Link. (2006). Sushi Rice Recipe. Retrieved from http://www.sushilinks.com/sushi-recipes/rice.html

University of Florida (2004). Guidance for processing sushi in retail operations. Retrieved from http://edis.ifas.ufl.edu/pdffiles/FS/FS11700.pdf

Urbanspoon. (2013). 73 Restaurants for "Sushi Burnaby”. Retrieved from http://www.urbanspoon.com/s/14?q=sushi+burnaby

U.S. Food and Drug Administration. (2008). Approximate pH of Foods and Food Products. Retrieved from http://www.foodscience.caes.uga.edu/extension/documents/fdaap proximatephoffoodslacf-phs.pdf

Wilson, C.L. \& Droby, S. Microbial Food Contamination. Florida: CRC Press LLC, 2001. Pp. 158-159. 